\title{
YELLOWSTONE LAKE: \\ AN EVALUATION OF PATTERNS IN PRODUCTIVITY
}

\author{
W. H. Romme \\ Departinent of Biology \\ Fort Lewis College \\ Durango, Colorado \\ D. H. Knight \\ Department of Botany \\ University of Wyoming \\ Laramie
}

\section{Objectives}

There is evidence to suggest that the primary productivity of Yellowstone Lake may have decreased during the last 1500 years, with an accelerated decline in the last 100 years. Shero and Parker (1977) analyzed diatom frustules preserved in lake sediments and described a gradual decrease in both numbers and volume of frustules over the past 1500 years, although species cornposition has remained relatively constant. Varley (1974, and personal communication) compared chemical analyses of lake water made in 1884 with recent analyses and found lower concentrations of several elements in the recent samples. He also notes that early visitors at the Lake Hotel often complained about the offensive smell of rotting "seaweed" piled 3-4 feet deep on the beach, whereas only scattered macrophyte detritus can be found on the lake shore today.

Most oligotrophic lakes appear to becorre more eutrophic with time (Lindemann 1942), so a progressive decline in the productivity of Yellowstone Lake leads to the question of why this lake shows a different pattern. The apparent drop in productivity also has important management implications, since Yellowstone take supports one of the last cemaining populations of the native cutthroat trout (Salmo clarkii) which once inhabited many of the mountain streains and lakes in this region. The trout in turn support a complex food web including otters, pelicans, eagles, ospreys, and bears. Yellowstone Lake is regarded as unpolluted, and most of its watershed is wilderness. Nevertheless, human activities such as fire suppression and removal of trout through sport fishing may have had sibtle effects on the nutrient budget of the lake, and may have contributed to the apparent sharp drop in productivity during the last century.

Thus, our research has three objectives:

1. Assemble, summarize, and evaluate existing data and observations related to the past and present trophic status of .Yellowstone Lake;

2. Identify all possible explanations for the observed patterns in lake productivity, both long-term (last 1500 years) and recent (last 100 years), and summarize and evaluate existing evidence to support or 
refute each proposed explanation; and

3. Collect new data to test one attractive hypothesis that has been mentioned frequently but never examined closely, namely that changes in the nutrient status and productivity of the lake are related, at least in part, to the effects of large fires in the watershed (Varley 1974, Rom me and Knight 1982).

Methods

To locate and assemble all existing data on the productivity and nutrient cyciing of Yellowstone Lake, we reviewed documents and records in the library at Mammoth Hot Springs and examined unpublished data and observations in files maintained by the U.S. Fish and Wildlife Service. The staff of the Fish and wildlife Service have been making detailed water chemistry analyses in several different parts of Yellowstone Lake since 1976, maintaining the data in computer files. They are now in the process of summarizing these measurements from the last 7 years to provide a baseline description of the lake's present conditions and the magnitude of yearly and seasonal variations in water chemistry. This summary will be included in our final report, and we gratefully acknowledge the assistance of the Fish and Wildlife Service staff in this matter. We have also obtained data on the chemistry of precipitation in Yellowstone National Park from the National Atmospheric Deposition Program, to evaluate the possible impact of regional air pollution (particularly acidic deposition) on Yellowstone Lake.

To identify and evaluate possible explanations for the changes in Yellowstone Lake, we conducted a computerized bibliographic search with the assistance of the University of Wyoming library. The search uncovered several hundred references to studies of productivity and nutrient cycling in temperate lakes around the world. We also talked with limnologists and paleo-ecologists at the annual meetings of the Ecological Society of America and the American Instibute of Biological Sciences in August, 1982.

To test the hypothesis that documented changes in the productivity and nutrient concentrations of Yellowstone Lake are related to the effects of large corest fires, we reconstructed fire history in the watershed of West Thumb. For this work we collected sections from fire-scarred trees and increinent cors from even-aged lodgepole pine forests of fire origin (Heinselman 1973, Arno and Sneck 1977, Romme 1982). Using these data and a forest cover map preparad by Don G. Despain, Yellowstone Park Biologist, we will construct a fire history map showing the present age and successional stage of all homogeneous forest units. We will then reconstruct past vegetation mosiacs in the watershed (Romme 1982). By comparing patterns in the diatoms preserved in the sediments of the South Arm (Shero and Parker 1977) and our reconstructed patterns in fire history and vegetational composition of the watershed, we expect to detect the connections, if any, between large fires and phytoplankton productivity. 
$\underline{\text { Results }}$

We have not yet completed our analyses, so only some preliminary results can be reported at this time. We expect to complete our final report during the spring and summer of 1983. It will be necessary to make one more brief trip to Yellowstone Park to collect additional fire history data frorn a remote portion of the watershed of the South Arm. All other necessary data were obtained during the field season of 1982.

We found evidence of at least eleven fires in the watershed of the South Arm during the last 400 years (Table 1). The largest was the fire of ca. 1750, which covered ca. 4300 ha. This area actually may have been burned by two or more smaller fires at short intervals between 1740 and 1770. To determine whether the extensive even-aged forests covering this large area resulted from one very large fire or from several smaller fires at short intervals would require intensive searching for fire-scarred relict trees, which are not common in this area. For the purposes of the present study, however, such a distinction probably is not critical; the significant facts are that mature forests in ca. $36 \%$ of the watershed were replaced by early successional stages in the mid-1700's, and that a disturbance of comparable magnitude has not occurred since then in this area.

When fire history is compared to historical patterns in diatom abundance, few obvious correlations are apparent (Table 2). A peak in diatoms in the late $1800^{\prime} \mathrm{s}$ does coincide with fires covering ca. $10 \%$ of the watershed in ca. 1870 and 1879. However, there was another peak in diatoms in the early 1800's when only $2 \%$ of the watershed burned, and a low point in diatoms in the early 1900's when $3 \%$ of the watershed burned. Unfortunately, the segments of the seliment core analyzed by Shero and Parker (1977) did not include the period around 1750, when the largest. fire occurced, so we cannot determine its effects on the phytoplankton.

The analysis presented above is preliminary only, so no firm conclusions can be drawn at this time. The effects of past fires may be obscured by the fact that the South Arm is very large and the sediment core examined by Shero and Parker (1977) came froin its center, hundreds of meters from the nearest shore. Nutrients entering the lake in runoff probably would be absorbed very rapidly by plankton near the shoreline, and might never reach the middle of the lake. On two occasions in 1982 we observed apparent plankton blooms at the mouths of inlet streamis, while the waters in most of the lake were as clear as usual. It may be significant that the fires of ca. 1870 and 1879, which were associated with an increase in diatoms, occurred on the west shore of the South Arm directly adjacent to the site of the sediment core. Thus, the sediment cores may reflect only relatively local changes and may not be representative of the lake as a whole, or even of one entire arm of the lake. However, all of these ideas are tentative at present.

\section{Conclusions}

Our analyses are not yet complete enough to draw any conclusions at this time. 
Table 1. Preliminary fire history in the 12,000-ha watershed of the South Arm of Yellowstone Lake. Fire sizes are estimates based on Field notes and forest cover maps; they will be refined and probably modified somewhat when additional analyses are completed. Some of the fires also burned in areas outside of the watershed, so their total size is larger than that reported here.

\begin{tabular}{rrc}
\hline 1981 & 500 & 5 \\
1976 & 600 & 5 \\
1953 & 50 & $<1$ \\
1940 & 500 & 4 \\
1931 & 500 & 4 \\
1910 & 300 & 3 \\
1879 & 900 & 8 \\
ca 1870 & 200 & 2 \\
ca 1810 & 200 & 2 \\
ca 1750 & 4,300 & 36 \\
ca 1680 & 500 & 4 \\
pre-1680 & $3,250^{a}$ & $26^{a}$ \\
\hline
\end{tabular}

a No evidence of fire in the last 400 years. 
Table 2. Fire history and historical patterns of diatom abundance in sediments of the South Arm of Yellowstone Lake. Diatom data are from Figures 2 and 10 in Shero and Parker (1977); dashes ( $\rightarrow$ mean that no data are available for that particular time period.

\begin{tabular}{|c|c|c|c|}
\hline XEARS & $\begin{array}{l}\text { O OF WATER- } \\
\text { SHED BURNED }\end{array}$ & $\begin{array}{l}\text { CORRECTED TOTAL } \\
\text { NUMBER OF FRUSTULES }\end{array}$ & $\begin{array}{l}\text { CORRECTED TOTAL } \\
\text { VOLUME OF FRUSTULES }\end{array}$ \\
\hline $1950-1975$ & $<1$ & 400 & 5,000 \\
\hline $1925-1950$ & 8 & - & - \\
\hline $1900-1925$ & 3 & 350 & 4,000 \\
\hline $1875-1900$ & 10 & 650 & 5,500 \\
\hline $1850-1875$ & 0 & 400 & 4,500 \\
\hline $1825-1850$ & 0 & - & - \\
\hline p800-1825 & 2 & 550 & 7,000 \\
\hline $1775-1800$ & 2 & 400 & $\cdot 4,000$ \\
\hline $1750-1775$ & 36 & - & - \\
\hline $1725-1750$ & 0 & - & - \\
\hline
\end{tabular}


When we complete our final repoct in the summer of 1983 we hope to be able to provide answers for many of the questions raised above.

\section{Titerature Cited}

Arno, S. F., and K. M. Sneck. 1977. A method for determining fire history in coniferous forests of the mountain west. USDA Forest Service, Gen. Tech. Rep. INT-42.

Heinselman, M. L. 1973. Fire in the virgin forests of the Boundary Waters Canoe Area, Minnesota. Quat. Res. 3:329-382.

Lindemann, R. I. 1942. The trophic-dynamic aspect of ecology. Ecology 23:399-417.

Romme, w. H. 1982. Fire and landscape diversity in subalpine forests of Yellowstone National Park. Ecol. Monographs 52:199-221.

Romme, W. H., and D. H. Knight. 1982. Landscape diversity: the concept applied to Yellowstone Park. BioScience 32:664-670.

Shero, B. R., and M. Parker. 1977. Limnological changes in Yellowstone Lake as indicated by sediment aiatoms. Final Report for Contract No. 43-8329.

Varley, J. D. 1974. A new look at angling regulations on Yellowstone Lake-1975. Yellowstone National Park, Information Paper No. 25. 